\title{
Purinergic Receptors in Adipose Tissue As Potential Targets in Metabolic Disorders
}

\author{
Marco Tozzi and Ivana Novak* \\ Section for Cell Biology and Physiology, Department of Biology, University of Copenhagen, Copenhagen, Denmark
}

Extracellular nucleosides and nucleotides, such as adenosine and adenosine triphosphate (ATP), are involved in many physiological and pathological processes in adipose tissue (AT). It is becoming accepted that, in addition to the well-established sympathetic and hormonal system, purinergic receptors contribute significantly to regulation of adipocyte functions. Several receptor subtypes for both adenosine (P1) and ATP (P2X and P2Y) have been characterized in white adipocytes (WA) and brown adipocytes (BA). The effects mediated by adenosine and ATP on adipocytes are multiple and often differing, depending on specific receptors activated. Using a variety of agonists, antagonists and transgenic animals it has been demonstrated that adenosine and P2 receptors are involved in lipolysis, lipogenesis, adipokines secretion, glucose uptake, adipogenesis, cell proliferation, inflammation, and other processes. Given their

OPEN ACCESS

Edited by:

Francisco Ciruela,

University of Barcelona, Spain

Reviewed by:

Alessandro Bartolomucci, University of Minnesota, United States Gennady G. Yegutkin, University of Turku, Finland

${ }^{*}$ Correspondence: Ivana Novak inovak@bio.ku.dk

Specialty section: This article was submitted to Experimental Pharmacology and Drug Discovery, a section of the journal Frontiers in Pharmacology

Received: 09 October 2017 Accepted: 13 November 2017 Published: 24 November 2017

Citation:

Tozzi M and Novak I (2017) Purinergic Receptors in Adipose Tissue As Potential Targets in Metabolic Disorders. Front. Pharmacol. 8:878. doi: 10.3389/fphar.2017.00878 central role in regulating many AT functions, purinergic receptors are considered potential therapeutic targets in different pathological conditions, such as obesity and type-2 diabetes. To achieve this goal, specific and potent P1 and P2 receptors activators and inhibitors are being developed and show promising results. However, more insight is needed into the function of P2 receptors in brown and beige adipocytes and their potential role in thermogenesis. This review aims at summarizing current knowledge on the patho-/physiological role of P1, P2X, and P2Y receptors in WA and BA and their potential exploitation for pharmacological intervention. Furthermore, we analyze impact of purinergic signaling in AT - in health and metabolic diseases.

Keywords: purinergic receptors, adenosine, ATP, adipocytes, obesity, type-2 diabetes, inflammation, adipose tissue

\section{INTRODUCTION}

Metabolic disorders, such as obesity, dyslipidemia, and hyperglycemia, are closely related to AT dysfunction, and indeed AT is considered one of the most promising therapeutic targets (Guilherme et al., 2008; Kusminski et al., 2016). AT is a metabolic and endocrine organ consisting mainly of adipocytes. In addition, AT contains other cell types collectively named SVF, which

Abbreviations: AT, adipose tissue; ADP, adenosine diphosphate; ATP, adenosine triphosphate; BA, brown adipocytes; BAT, brown adipose tissue; BzATP, 2'-3'-O-(4-benzoylbenzoyl)-ATP; cAMP, cyclic AMP; FFAs, free fatty acids; HFD, high fat diet; IL-, interleukin; KO, knockout; MSCs, mesenchymal stem cells; PAI-1, plasminogen activator inhibitor-1; PKA, protein kinase A; PLC, phospholipase C; SVF, stromal vascular fraction; TNF $\alpha$, tumor necrosis factor- $\alpha$; UCP1, uncoupling protein-1; UDP, uridine diphosphate; UTP, uridine triphosphate; VNUT, vesicular nucleotide transporter; WA, white adipocytes; WAT, white adipose tissue. 
includes MSCs, preadipocytes, endothelial cells, fibroblasts, and a variety of immune cells such as macrophages and $\mathrm{T}$ regulatory cells. Mammals have two main types of AT: WAT comprises mainly of WA, which store excess energy as triglycerides; and BAT, characterized by mitochondria-rich adipocytes, which express UCP1 that enables dissipation of energy by production of heat. Within WAT, there are also UCP1-positive cells with thermogenic capacity called beige or brite (brown-in-white) adipocytes. Cold exposure or other specific factors can produce browning of WAT (Harms and Seale, 2013; Kim and Plutzky, 2016). WAT and BAT are innervated by the sympathetic nervous system that together with hormones and other factors regulates adipocyte function (Bulloch and Daly, 2014). Adipocytes are also regulated by nucleosides and nucleotides, such as adenosine and ATP.

Generally, ATP is released from sympathetic nerves (Burnstock, 2007) and this is also likely in AT (Gnad et al., 2014), though only sympathetic nerves innervating BAT were found to express the ATP transporter VNUT (Razzoli et al., 2016). Many other non-excitable cells, such as epithelial, glial, stromal, and immune cells release ATP in basal conditions (Corriden and Insel, 2010) and in response to various patho-/physiological stimuli (Junger, 2011; Novak, 2011; Lazarowski, 2012). Similarly, ATP could be released from adipocytes (Gnad et al., 2014; Adamson et al., 2015). The mechanism of ATP release is not extensively studied; so far one study suggests channel pannexin-1 (Adamson et al., 2015) and another vesicular-based mechanism (Razzoli et al., 2016). Other cells in AT could also release ATP, contributing to a purinergic cross-talk between different cells, but such signaling is yet to be explored. In the extracellular space ATP is hydrolyzed to adenosine by one or more ecto-nucleotidases belonging to four families: ecto-nucleoside triphosphate diphosphorylases (CD39 type), ecto-5'-nucleotidase (CD73 type), ecto-nucleotide pyrophosphatase/phosphodiesterases (NPP) and alkaline phosphatases (APs) (Zimmermann et al., 2012). Interestingly, one of the enzymes NPP2, also known as phospholipase D or autotaxin, is multifunctional and released by adipocytes, and up-regulated autotaxin expression correlates with obesity (Rancoule et al., 2014). Nevertheless, it is most often assumed that adipocytes can release adenosine, possibly through nucleoside transporters (Antonioli et al., 2008; Gnad et al., 2014).

Adenosine, ATP, and other nucleotides signal through purinergic receptors that operate in virtually all mammalian cells, and it can be disturbed in various diseases, including metabolic syndrome, and therefore is attractive for therapeutic targeting (Burnstock, 2013; Burnstock and Novak, 2013; Chen et al., 2013; Jacobson and Muller, 2016). Here, we summarize the current knowledge about (i) the expression and function of adenosine receptors (P1R) and $\mathrm{P} 2$ receptors (P2XR and $\mathrm{P} 2 \mathrm{YR}$ ) in white, brown, and possibly in beige adipocytes; (ii) their role in the onset and progression of metabolic disorders; and (iii) their potential as therapeutic targets. In some cases, it is difficult to dissect the contribution of purinergic signaling in adipocytes from the AT/whole body effects (Peleli and Carlstrom, 2017). This is because the SVF in AT and other organs express purinergic receptors, and various conditions (e.g., inflammation) and experimental set up (e.g., whole-body receptor KOs or systemic receptor modulators) will complicate interpretation of effects.

\section{ADENOSINE RECEPTORS IN ADIPOSE TISSUE}

Adenosine accumulates extracellularly in response to metabolic stress, tissue injury, hypoxia and inflammation and concentrations can range from nanomolar to micromolar in physiological and pathophysiological conditions, respectively (Fredholm, 2014). Adenosine can bind to four different G-protein-coupled receptors $A_{1}, A_{2 A}, A_{2 B}$, and $A_{3} . A_{1} R$ and $A_{2 A} R$ have high affinity for adenosine, while $A_{2 B} R$ and $A_{3} R$ have relatively lower affinity. $A_{1} R$ and $A_{3} R$ are coupled to $G_{i / o}$ proteins and their activation inhibits cAMP production and decreases PKA activity. $A_{2 A} R$ and $A_{2 B} R$ are coupled to $G_{s}$ olf proteins and stimulate cAMP production, thus activating PKA. In addition, some adenosine receptors also activate $\mathrm{PLC}, \mathrm{Ca}^{2+}$ signaling and mitogen-activated protein kinases (Fredholm et al., 2011).

Adenosine has a key role in regulating many patho/physiological processes in AT and adipocytes (Figure 1). The most studied adenosine receptor is the $A_{1}$, identified in WAT of many species (Trost and Schwabe, 1981; Larrouy et al., 1991; Strong et al., 1993; Mersmann et al., 1997; Tatsis-Kotsidis and Erlanger, 1999). Using pharmacological tools and whole body $\mathrm{A}_{1} \mathrm{R} \mathrm{KO}$ mice, it was shown that activation of this receptor in rodents has anti-lipolytic effects mediated by inhibition of cAMP production and decrease in PKA and lipase activities (Fredholm, 1978; Schoelch et al., 2004; Dhalla et al., 2007a; Johansson et al., 2008). Rat WA are more responsive than BA to inhibition of lipolysis by the $\mathrm{A}_{1} \mathrm{R}$ stimulators PIA and NECA (Saggerson and Jamal, 1990), probably due to higher expression of the receptor in WA (Gnad et al., 2014). $\mathrm{A}_{1} \mathrm{R}$ activation also increases lipogenesis in mouse and rat WA (Johansson et al., 2008; Szkudelski et al., 2009). The $A_{1} R$ is also implicated in adipogenesis (Gharibi et al., 2012) and leptin production in WA (Cheng et al., 2000; Rice et al., 2000). All these $A_{1}$ R-mediated effects highlight the importance of adenosine signaling in AT, and predict impact on whole body metabolism. In accordance, $\mathrm{A}_{1} \mathrm{R}$ KO mice have increased fat mass and body weight, and impaired glucose tolerance and insulin sensitivity (Faulhaber-Walter et al., 2011; Yang et al., 2015). In contrast, mice overexpressing the $\mathrm{A}_{1} \mathrm{R}$ in $\mathrm{AT}$ are protected from obesity-induced insulin resistance (Dong et al., 2001).

Another fairly well studied receptor is the $A_{2 B} R$, detected in adipocytes and SVF (Gnad et al., 2014). In vitro experiments on murine pre-osteoblast cell line expressing either human $\mathrm{A}_{2 \mathrm{~B}} \mathrm{R}$ or $A_{1} R$ showed that $A_{1} R$ stimulated adipogenesis, while the $\mathrm{A}_{2 \mathrm{~B}} \mathrm{R}$ inhibited both adipogenesis and lipogenesis, supporting osteoblastogenesis pathways (Gharibi et al., 2012). In in vivo experiments, $\mathrm{A}_{2 \mathrm{~B}} \mathrm{R}$ expression seems to correlate with parameters of obesity, both in rodents and humans, and the receptor is upregulated in visceral AT of mice fed HFD (Johnston-Cox et al., 2012). Genetic KO of the receptor is also associated with metabolic disorders. Whole body $\mathrm{A}_{2 \mathrm{~B}} \mathrm{R} \mathrm{KO}$ led to $\mathrm{AT}$ 


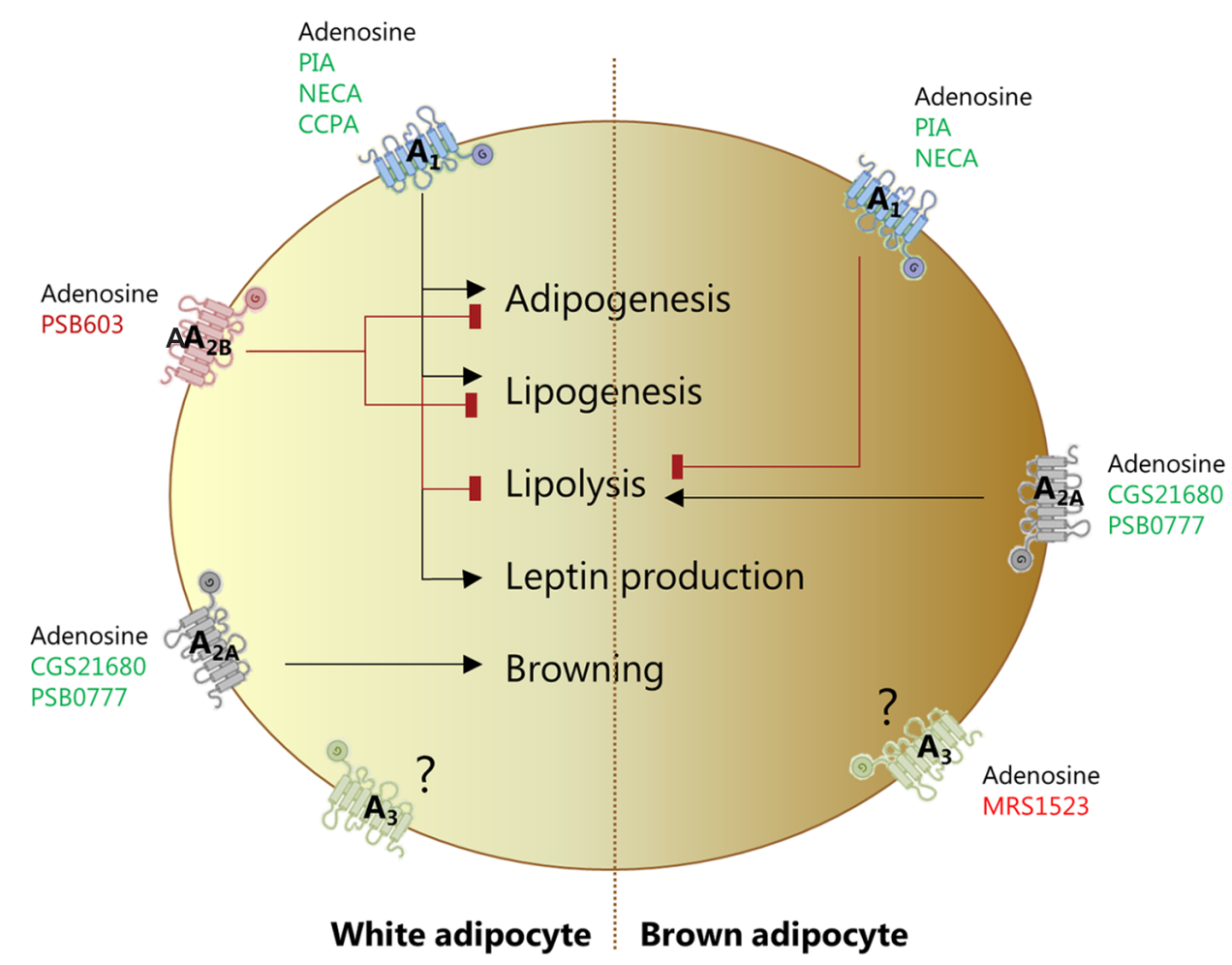

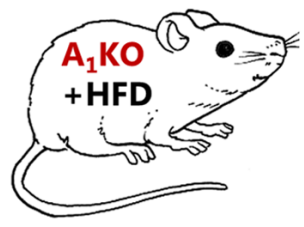

$\downarrow$ Glucose tolerance

$\downarrow$ Insulin sensitivity

$\uparrow$ Body fat

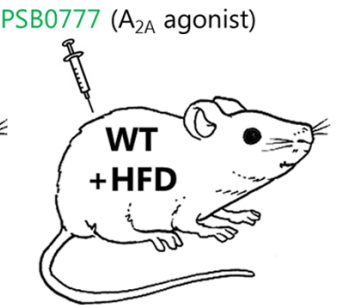

$\uparrow$ Glucose tolerance \obesity $\uparrow$ energy expenditure

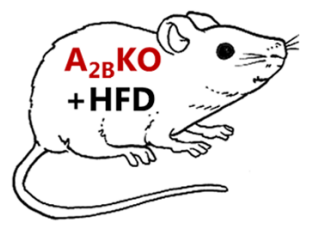

$\downarrow$ Glucose tolerance $\downarrow$ Insulin sensitivity $\uparrow$ AT inflammation
BAY60-6583 ( $\mathrm{A}_{2 \mathrm{~B}}$ agonist)

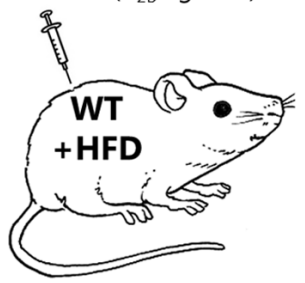

$\uparrow$ Glucose tolerance

$\uparrow$ Insulin sensitivity

$\downarrow$ AT inflammation

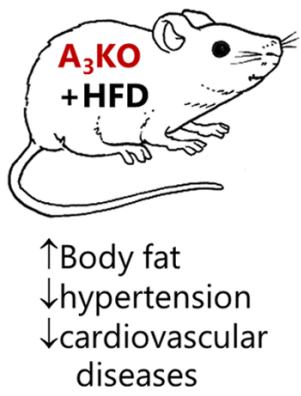

FIGURE 1 | Effect of pharmacological and genetic modulation of adenosine receptors in white (left) and brown (right) adipocytes and in various mouse models. The figure shows agonists (green), antagonists (red) and knockout animals (red) that have been used in the studies quoted in this review to address the function of the specific receptor.

inflammation, insulin resistance, impaired glucose and lipid metabolism in mice (Johnston-Cox et al., 2012; Csoka et al., 2014; Peleli et al., 2015). Importantly, systemic administration of the $A_{2 B}$ specific agonist BAY 60-6583, following HFD regime, lowered plasma glucose, insulin and IL- 6 levels, and ameliorated type-2 diabetes in mice (Johnston-Cox et al., 2012). These animal studies and a recent study (Johnston-Cox et al., 2014) are interpreted mainly in terms of the $A_{2 B} R$ activation of WAT macrophage. Nevertheless, involvement of adipocyte $A_{2 B} R$ cannot be excluded.

The $\mathrm{A}_{2 \mathrm{~A}} \mathrm{R}$ may have a major role in BAT, where it is more abundantly expressed compared to WAT (Gnad et al., 2014). Early studies showed that adenosine inhibited lipolysis in $\mathrm{BA}$ from rat or hamster, probably via $\mathrm{A}_{1} \mathrm{R}$ (Schimmel and McCarthy, 1984; Woodward and Saggerson, 1986). In contrast, recent work shows that adenosine and $\mathrm{A}_{2 \mathrm{~A}} \mathrm{R}$ agonists (CGS21680 or PSB-0777) activated lipolysis in human and murine BA, and to explain differences in the studies authors proposed species-related differential receptor expression (Gnad et al., 2014). Moreover, agonists used in this study increased energy expenditure, induced browning of WAT, improved glucose tolerance and protected $\mathrm{C} 57 \mathrm{Bl} / 6$ mice from diet-induced obesity, thus revealing a promising thermogenic effect of adenosine. Similar effect on glucose homeostasis was reported for another $\mathrm{A}_{2 \mathrm{~A}} \mathrm{R}$ agonist CGS21680 administered to Swiss strain mice fed with HFD (DeOliveira et al., 2017). No alteration in body weight 
or adiposity was detected, though decrease in some inflammatory markers was observed. The difference in animal obesity detected in the two studies could be due to different time regimes of drug treatment ( 8 weeks vs. 2 weeks), differences in strains of mice used (see below for comments on $\mathrm{C} 57 \mathrm{Bl} / 6$ strain), or specificity of different $\mathrm{A}_{2 \mathrm{~A}} \mathrm{R}$ agonists used.

There are only a few studies on $A_{3} R$ in adipocytes/AT. Isolated human WA express higher levels of $\mathrm{A}_{3} \mathrm{R}$ mRNA compared to BA. But inhibition of the receptor with MRS1523 had no significant effect on modulating lipolysis, at least in murine BA (Gnad et al., 2014). However, the $\mathrm{A}_{3} \mathrm{R} \mathrm{KO}$ mice had less abdominal and total body fat, and mice were protected from hypertension and cardiovascular diseases in the chronic kidney disease model tested (Yang et al., 2016).

Taken together, there is strong evidence that adipocytes express all types of adenosine receptors that regulate patho/physiological processes (Figure 1). There is a consensus that $\mathrm{A}_{1} \mathrm{R}$ regulates lipolysis and therefore FFAs levels, which play a significant role in the pathogenesis of insulin resistance, diabetes, and cardiovascular diseases (Dhalla et al., 2009; Antonioli et al., 2015). Several $A_{1}$ R agonists, e.g., SDZWAG994 (Ishikawa et al., 1998), ARA (Zannikos et al., 2001), and RPR749 (Shah et al., 2004), have been clinically evaluated as antilipolytic agents for the treatment of hypertriglyceridemia and type- 2 diabetes. Though, development of full $\mathrm{A}_{1} \mathrm{R}$ agonists has been limited by (i) the debilitating side effects induced by the activation of the receptors in heart and kidney of animal models (Belardinelli et al., 1989; Wu et al., 2001); and (ii) a well-characterized desensitization of the receptor after repeated exposure to full agonists (Hoffman et al., 1986; Dhalla et al., 2007b). However, selective partial $A_{1} R$ agonists, e.g., CPA and GS-9667 (CVT-3619), effectively lowered plasma FFA levels without detectable cardiovascular side effects in rodents and humans (Dhalla et al., 2007a,b). These effects were achieved by administering lower concentrations of these drugs, which acted predominantly on $\mathrm{AT}$, as it has larger $\mathrm{A}_{1} \mathrm{R}$ reserve compared to other tissues (i.e., atrioventricular node) (Staehr et al., 2013). Furthermore, given the role of the $\mathrm{A}_{2 \mathrm{~B}} \mathrm{R}$ in glucose and lipid homeostasis, and AT inflammation, this receptor could be a promising target for the treatment of metabolic diseases. Finally, finding that activation of $\mathrm{A}_{2 \mathrm{~A}} \mathrm{R}$ induces beiging of WA and activates BA (Gnad et al., 2014) may stimulate development of new pharmacological interventions for the treatment of obesity and metabolic disease.

\section{PURINERGIC P2 RECEPTORS IN ADIPOSE TISSUE}

In contrast to adenosine, patho-/physiological functions of ATP and other nucleotides have not been studied so extensively in AT. Tri- and di-nucleotides signal through P2R belonging to two main families: the ionotropic P2XRs and the metabotropic G-protein coupled P2YRs. The P2XRs (P2X1-7) are ligandgated cation channels activated primarily by ATP (North, 2016). The P2YR subtypes can be stimulated by different endogenous nucleotides and most potent ones (in humans) are given in brackets. P2Y1R (ADP), P2Y2R (UTP), P2Y4R (UTP), P2Y6R (UDP) receptors couple to $\mathrm{G}_{\mathrm{q}}$ proteins and thus activate PLC- $\beta$, mobilizing $\mathrm{Ca}^{2+}$ from intracellular stores. P2Y11R (ATP) couple in addition to $\mathrm{G}_{\mathrm{s}}$ proteins increase cAMP, while P2Y12R (ADP), P2Y13R (ADP), and P2Y14R (UDP, UDP-glucose) couple to $\mathrm{G}_{\mathrm{i}}$ proteins and inhibit cAMP formation (von Kugelgen and Hoffmann, 2016).

Early studies by Lee and Pappone (1997a,b) and Lee S.C. et al. (2005) used patch-clamp, $\mathrm{Ca}^{2+}$ imaging and mRNA analysis to fingerprint functional P2XRs and P2YRs in WA and BA. Here, we will focus on role of P2Rs in regulating multiple adipocytespecific processes as summarized in Figure 2.

P2Rs regulate adipogenesis. Several studies used expression profiling and functional assays to describe that P2Y1R, P2Y2R or $\mathrm{P} 2 \mathrm{Y} 4 \mathrm{R}$ and $\mathrm{P} 2 \mathrm{Y} 11 \mathrm{R}$ positively affected adipogenic differentiation of stem cells derived from bone marrow or AT (Kawano et al., 2006; Zippel et al., 2012; Ciciarello et al., 2013; Li et al., 2016). In contrast, P2Y4R activation (UTP, MRS4062) inhibited cardiac AT-derived stem cells differentiation and P2Y4R KO mice developed bigger cardiac AT mass and higher expression of UCP1 (Lemaire et al., 2017). The opposite effect of P2Y4R in the mentioned studies could be related to the higher receptor expression in cardiac AT compared to other fat depots and/or beige/BA lineage in the cardiac tissue. Three other receptors have anti-adipogenic effects - P2Y13, P2Y14, and P2X7 (Zippel et al., 2012; Biver et al., 2013). Interestingly, P2X7R KO male mice had increased body weight, adipocyte hyperplasia in fat pads, and ectopic lipid accumulation in kidney, salivary glands, and pancreas (Beaucage et al., 2014). Other in vitro and in vivo studies indicate that the P2X7R stimulation directs differentiation of MSCs toward the osteoblast lineage rather than toward adipocytes (Li et al., 2015).

P2Rs are also implicated in lipid metabolism. One study on isolated rat WA shows that ATP, UTP, and BzATP, probably by activating different P2Rs, had dual effects - activated lipolysis and inhibited insulin-induced leptin production (Lee $\mathrm{H}$. et al., 2005). In contrast, no lipolytic effect of ATP was found in a similar cellular model (Schodel et al., 2004). The explanation for these divergent results could be that the two studies used different ATP concentrations, thus affecting different palette of P2Rs. Furthermore, in the latter study on isolated WA, ATP stimulated lipogenesis but had no effect on glucose transport (Schodel et al., 2004).

The role of purinergic signaling in glucose uptake in adipocytes has been investigated in 1980s. Two studies showed that low concentrations of ATP inhibited insulin-stimulated glucose transport in rat fat cells (Chang and Cuatrecasas, 1974; Halperin et al., 1978), and it was assumed that extracellular ATP had direct inhibitory effect on the insulin receptor. More recently, it was shown that P2Y6R activation by UDP or MRS2957 increased GLUT-4 translocation and glucose uptake in primary WA and 3T3-L1 cells (Balasubramanian et al., 2014).

In addition to effects on adipogenesis, lipid metabolism, and glucose transport, P2Rs affect leptin and adiponectin production and secretion, but activation of different P2R subtypes might lead to opposite effects. ATP and BzATP reduced leptin mRNA levels and inhibited insulin-induced leptin secretion in rat WA (Lee H. 


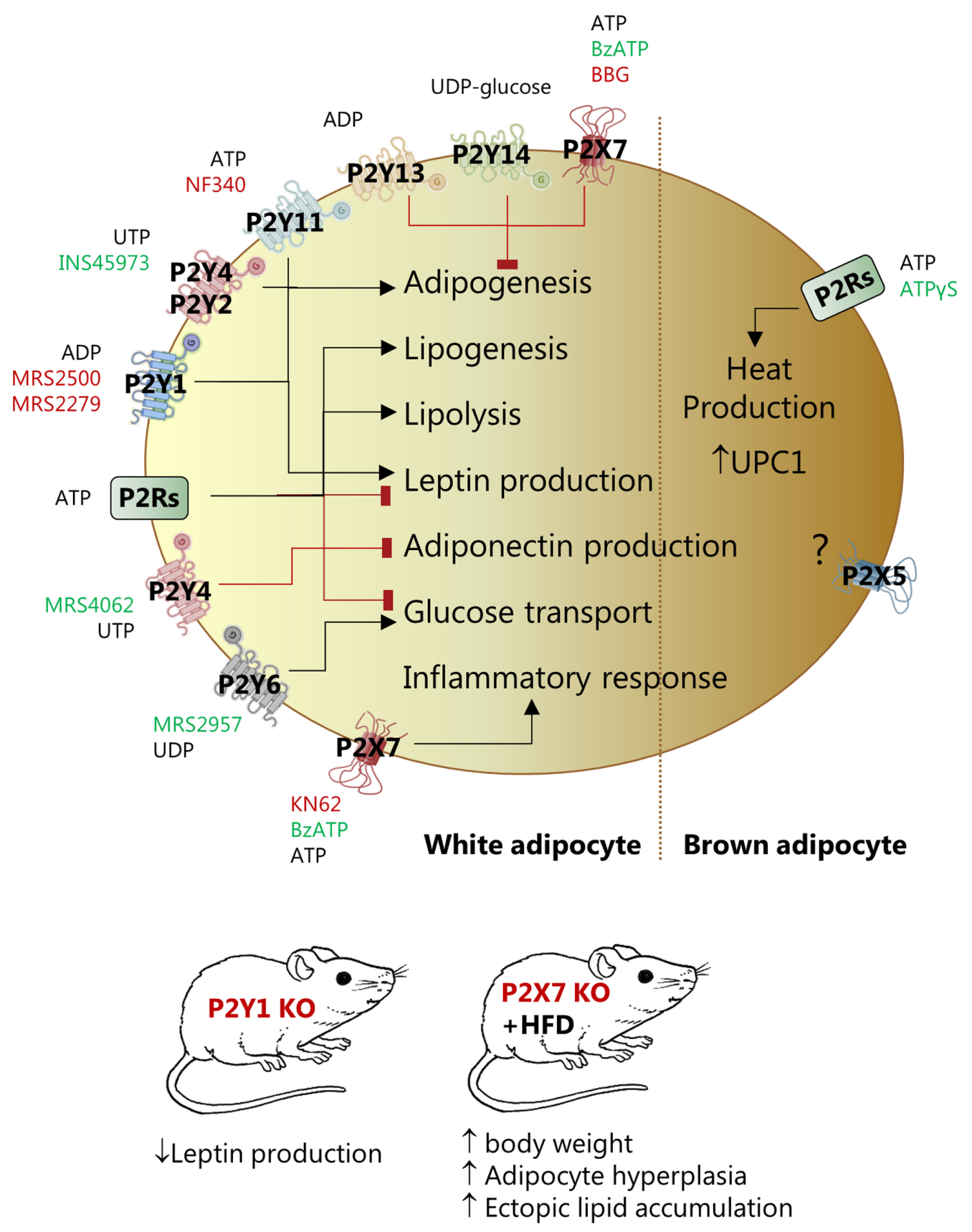

FIGURE 2 | Effect of pharmacological and genetic modulation of P2X and P2Y receptors in white (left) and brown (right) adipocytes and in various mouse models. The figure lists agonists (green), antagonists (red) and knockout animals (red) that have been used in the studies quoted in this review to address the function of the specific receptor.

et al., 2005). In another study, inhibition of P2Y1R by MRS2500 decreased leptin production under basal and insulin-stimulated conditions in isolated mouse WA (Laplante et al., 2010). Furthermore, the study showed that plasma leptin was lower in mice lacking P2Y1R, however, in mice on HFD the plasma leptin was enhanced and the inhibitory effect of receptor KO was not observed. Stimulation of P2Y4R by UTP or MRS4062 inhibited adiponectin expression and secrection in cardiac adipocytes and
P2Y4R KO mice showed increased adiponectin secrection in hypoxia and a cardioprotective phenotype (Lemaire et al., 2017).

Adenosine triphosphate is generally considered as an inflammatory molecule (Idzko et al., 2014). Particularly the P2X7R mediates inflammation in AT. In primary adipocytes from rat epididymal fat, millimolar concentrations of ATP evoked inflammatory response and led to impaired insulin signaling and glucose uptake (Yu and Jin, 2010). Visceral and subcutaneous 
human AT express functional P2X7R, which could be involved in release of inflammatory cytokines such as IL-6, TNF $\alpha$, and PAI-1 (Madec et al., 2011). Interestingly, this study showed that P2X7R expression appeared to be high in adipocytes isolated from subjects affected by metabolic syndrome. The P2X7R and NLRP3 inflammasome expression and IL-1 $\beta$ secretion was elevated in metabolically unhealthy obese individuals and the receptor expression correlated with body mass index and metabolic syndrome scores (Pandolfi et al., 2015). Whether this was due to effects on adipocytes or infiltrating immune cells is not clear (Pandolfi et al., 2016). In contrast, an earlier study concluded that the P2X7R was not involved in obesity-associated inflammasome activation. This was based on the observation that P2X7R KO mice on the C57BL/6 background and fed on HFD were not protected from obesity, AT inflammation and associated metabolic abnormalities (Sun et al., 2012). The C57BL/6 mice though have a single nucleotide polymorphism in the P2X7R that compromises the immune response (Rissiek et al., 2015), which could explain discrepancies in inflammasome activation in the two studies.

Rodent BA, express several P2X and P2Y receptors and stimulation with ATP leads to exocytosis and heat production (Lee and Pappone, 1997a; Lee S.C. et al., 2005). In a more recent study, ATP $\gamma \mathrm{S}$, enhanced UCP1 expression and induced browning in BAT in conditions of low adaptive thermogenesis and b-adrenergic receptor $\mathrm{KO}$ mice (Razzoli et al., 2016). This effect is most likely exerted via more than one receptor and P2X5R, P2X7R, and P2Y12R are overexpressed in $\beta$-less BAT. Interestingly, $\mathrm{P} 2 \mathrm{X} 5 \mathrm{R}$ is proposed as a novel cell surface marker for beige and BA as its mRNA levels are markedly higher in mouse BAT compared to WAT and other tissues (Ussar et al., 2014). Furthermore, the P2X5R expression increased in both BAT and subcutaneous WAT upon chronic cold exposure, paralleling expression of UCP1 (Ussar et al., 2014; Garcia et al., 2016; Razzoli et al., 2016). However, mechanisms of P2X5R mediated effects in AT are unknown.

Taken together, there is good evidence that P2Rs affect a wide range of patho-/physiological processes in rodent and human AT. Many of these processes, e.g., lipid deposition, metabolism, endocrine activity, and inflammation, are deregulated during pathological states such as obesity and diabetes. However, P2Rs

\section{REFERENCES}

Adamson, S. E., Meher, A. K., Chiu, Y. H., Sandilos, J. K., Oberholtzer, N. P., Walker, N. N., et al. (2015). Pannexin 1 is required for full activation of insulinstimulated glucose uptake in adipocytes. Mol. Metab. 4, 610-618. doi: 10.1016/ j.molmet.2015.06.009

Antonioli, L., Blandizzi, C., Csoka, B., Pacher, P., and Hasko, G. (2015). Adenosine signalling in diabetes mellitus-pathophysiology and therapeutic considerations. Nat. Rev. Endocrinol. 11, 228-241. doi: 10.1038/nrendo.2015.10

Antonioli, L., Fornai, M., Colucci, R., Ghisu, N., Tuccori, M., Del, T. M., et al. (2008). Regulation of enteric functions by adenosine: pathophysiological and pharmacological implications. Pharmacol. Ther. 120, 233-253. doi: 10.1016/j. pharmthera.2008.08.010

Balasubramanian, R., Robaye, B., Boeynaems, J. M., and Jacobson, K. A. (2014). Enhancement of glucose uptake in mouse skeletal muscle cells and adipocytes by P2Y6 receptor agonists. PLOS ONE 9:e116203. doi: 10.1371/journal.pone. 0116203 modulators have not yet been tested in clinical trials for treatment of metabolic disorders. Future research is still needed to dissect functions of P2R subtypes in adipocytes and AT before best P2R targets and drugs are selected.

\section{CONCLUSION AND PERSPECTIVES}

In this review, we discussed contribution of $\mathrm{P} 1$ and $\mathrm{P} 2$ receptors to modulation of AT functions and considered processes that may underlie their role in metabolic disorders. Several preclinical studies indicate that pharmacological manipulation of purinergic signaling in adipocytes and AT has interesting potential for treating metabolic disorders. However, translation of these findings into clinical trials will require more detailed knowledge about the role of extracellular ATP and adenosine in the onset and progression of obesity-related disorders, as well as about the basic physiology and pharmacology of purinergic receptors expressed in adipocytes and in AT. In this context, it will be necessary to: (i) know differential expression of adenosine and P2Rs in white, brown and beige adipocytes belonging to different fat depots (subcutaneous, visceral, cardiac etc.); (ii) clarify sources and concentrations of nucleotides/sides and modifying enzymes present in specific AT microenvironments; (iii) understand role of purinergic system in interplay between different cells in AT microenvironment and potential patho-/physiological conditions which may affect those.

\section{AUTHOR CONTRIBUTIONS}

MT wrote the draft and prepared figures. IN contributed to planning and writing of the review.

\section{FUNDING}

Work in our laboratory that inspired this review was funded by the Independent Research Fund Denmark/Natural Sciences (4002-00162B).

Beaucage, K. L., Xiao, A., Pollmann, S. I., Grol, M. W., Beach, R. J., Holdsworth, D. W., et al. (2014). Loss of P2X7 nucleotide receptor function leads to abnormal fat distribution in mice. Purinergic Signal. 10, 291-304. doi: 10.1007/s11302013-9388- $\mathrm{x}$

Belardinelli, L., Linden, J., and Berne, R. M. (1989). The cardiac effects of adenosine. Prog. Cardiovasc. Dis. 32, 73-97. doi: 10.1016/0033-0620(89)90015-7

Biver, G., Wang, N., Gartland, A., Orriss, I., Arnett, T. R., Boeynaems, J. M., et al. (2013). Role of the P2Y13 receptor in the differentiation of bone marrow stromal cells into osteoblasts and adipocytes. Stem Cells 31, 2747-2758. doi: 10.1002/stem.1411

Bulloch, J. M., and Daly, C. J. (2014). Autonomic nerves and perivascular fat: interactive mechanisms. Pharmacol. Ther. 143, 61-73. doi: 10.1016/j. pharmthera.2014.02.005

Burnstock, G. (2007). Physiology and pathophysiology of purinergic neurotransmission. Physiol. Rev. 87, 659-797. doi: 10.1152/physrev.00043.2006

Burnstock, G. (2013). Purinergic signalling: pathophysiology and therapeutic potential. Keio J. Med. 62, 63-73. doi: 10.2302/kjm.2013-0003-RE 
Burnstock, G., and Novak, I. (2013). Purinergic signalling and diabetes. Purinergic Signal. 9, 307-324. doi: 10.1007/s11302-013-9359-2

Chang, K. J., and Cuatrecasas, P. (1974). Adenosine triphosphate-dependent inhibition of insulin-stimulated glucose transport in fat cells. Possible role of membrane phosphorylation. J. Biol. Chem. 249, 3170-3180.

Chen, J. F., Eltzschig, H. K., and Fredholm, B. B. (2013). Adenosine receptors as drug targets-what are the challenges? Nat. Rev. Drug Discov. 12, 265-286. doi: $10.1038 / \mathrm{nrd} 3955$

Cheng, J. T., Liu, I. M., Chi, T. C., Shinozuka, K., Lu, F. H., Wu, T. J., et al. (2000). Role of adenosine in insulin-stimulated release of leptin from isolated white adipocytes of Wistar rats. Diabetes Metab. Res. Rev. 49, 20-24. doi: 10.2337/ diabetes.49.1.20

Ciciarello, M., Zini, R., Rossi, L., Salvestrini, V., Ferrari, D., Manfredini, R., et al. (2013). Extracellular purines promote the differentiation of human bone marrow-derived mesenchymal stem cells to the osteogenic and adipogenic lineages. Stem Cells Dev. 22, 1097-1111. doi: 10.1089/scd.2012. 0432

Corriden, R., and Insel, P. A. (2010). Basal release of ATP: an autocrine-paracrine mechanism for cell regulation. Sci. Signal. 3:re1. doi: 10.1126/scisignal.3104re1

Csoka, B., Koscso, B., Toro, G., Kokai, E., Virag, L., Nemeth, Z. H., et al. (2014). $\mathrm{A} 2 \mathrm{~B}$ adenosine receptors prevent insulin resistance by inhibiting adipose tissue inflammation via maintaining alternative macrophage activation. Diabetes Metab. Res. Rev. 63, 850-866. doi: 10.2337/db13-0573

DeOliveira, C. C., Paiva Caria, C. R., Ferreira Gotardo, E. M., Ribeiro, M. L., and Gambero, A. (2017). Role of A1 and A2A adenosine receptor agonists in adipose tissue inflammation induced by obesity in mice. Eur. J. Pharmacol. 799, 154-159. doi: 10.1016/j.ejphar.2017.02.017

Dhalla, A. K., Chisholm, J. W., Reaven, G. M., and Belardinelli, L. (2009). A1 adenosine receptor: role in diabetes and obesity. Handb. Exp. Pharmacol. 193, 271-295. doi: 10.1007/978-3-540-89615-9_9

Dhalla, A. K., Santikul, M., Smith, M., Wong, M. Y., Shryock, J. C., and Belardinelli, L. (2007a). Antilipolytic activity of a novel partial A1 adenosine receptor agonist devoid of cardiovascular effects: comparison with nicotinic acid. J. Pharmacol. Exp. Ther. 321, 327-333.

Dhalla, A. K., Wong, M. Y., Voshol, P. J., Belardinelli, L., and Reaven, G. M. (2007b). A1 adenosine receptor partial agonist lowers plasma FFA and improves insulin resistance induced by high-fat diet in rodents. Am. J. Physiol. Endocrinol. Metab. 292, E1358-E1363.

Dong, Q., Ginsberg, H. N., and Erlanger, B. F. (2001). Overexpression of the A1 adenosine receptor in adipose tissue protects mice from obesity-related insulin resistance. Diabetes Obes. Metab. 3, 360-366. doi: 10.1046/j.1463-1326.2001. 00158.x

Faulhaber-Walter, R., Jou, W., Mizel, D., Li, L., Zhang, J., Kim, S. M., et al. (2011). Impaired glucose tolerance in the absence of adenosine A1 receptor signaling. Diabetes Metab. Res. Rev. 60, 2578-2587. doi: 10.2337/db 11-0058

Fredholm, B. B. (1978). Effect of adenosine, adenosine analogues and drugs inhibiting adenosine inactivation on lipolysis in rat fat cells. Acta Physiol. Scand. 102, 191-198. doi: 10.1111/j.1748-1716.1978.tb06062.x

Fredholm, B. B. (2014). Adenosine-a physiological or pathophysiological agent? J. Mol. Med. (Berl) 92, 201-206. doi: 10.1007/s00109-013-1101-6

Fredholm, B. B., IJzerman, A. P., Jacobson, K. A., Linden, J., and Muller, C. E. (2011). International union of basic and clinical pharmacology. LXXXI. Nomenclature and classification of adenosine receptors-an update. Pharmacol. Rev. 63, 1-34. doi: 10.1124/pr.110.003285

Garcia, R. A., Roemmich, J. N., and Claycombe, K. J. (2016). Evaluation of markers of beige adipocytes in white adipose tissue of the mouse. Nutr. Metab. (Lond). 13:24. doi: 10.1186/s12986-016-0081-2

Gharibi, B., Abraham, A. A., Ham, J., and Evans, B. A. (2012). Contrasting effects of $\mathrm{A} 1$ and $\mathrm{A} 2 \mathrm{~b}$ adenosine receptors on adipogenesis. Int. J. Obes. (Lond). 36, 397-406. doi: 10.1038/ijo.2011.129

Gnad, T., Scheibler, S., von, K. I, Scheele, C., Kilic, A., Glode, A., et al. (2014). Adenosine activates brown adipose tissue and recruits beige adipocytes via $\mathrm{A} 2 \mathrm{~A}$ receptors. Nature 516, 395-399. doi: 10.1038/nature13816

Guilherme, A., Virbasius, J. V., Puri, V., and Czech, M. P. (2008). Adipocyte dysfunctions linking obesity to insulin resistance and type 2 diabetes. Nat. Rev. Mol. Cell Biol. 9, 367-377. doi: 10.1038/nrm2391
Halperin, M. L., Mak, M. L., and Taylor, W. M. (1978). Control of glucose transport in adipose tissue of the rat: role of insulin, ATP, and intracellular metabolites. Can. J. Biochem. 56, 708-712. doi: 10.1139/o78-106

Harms, M., and Seale, P. (2013). Brown and beige fat: development, function and therapeutic potential. Nat. Med. 19, 1252-1263. doi: 10.1038/nm.3361

Hoffman, B. B., Chang, H., Dall'Aglio, E., and Reaven, G. M. (1986). Desensitization of adenosine receptor-mediated inhibition of lipolysis. The mechanism involves the development of enhanced cyclic adenosine monophosphate accumulation in tolerant adipocytes. J. Clin. Invest. 78, 185-190. doi: 10.1172/JCI112550

Idzko, M., Ferrari, D., and Eltzschig, H. K. (2014). Nucleotide signalling during inflammation. Nature 509, 310-317. doi: 10.1038/nature13085

Ishikawa, J., Mitani, H., Bandoh, T., Kimura, M., Totsuka, T., and Hayashi, S. (1998). Hypoglycemic and hypotensive effects of 6-cyclohexyl-2'-O-methyladenosine, an adenosine Al receptor agonist, in spontaneously hypertensive rat complicated with hyperglycemia. Diabetes Res. Clin. Pract. 39, 3-9. doi: $10.1016 /$ S0168-8227(97)00116-2

Jacobson, K. A., and Muller, C. E. (2016). Medicinal chemistry of adenosine, P2Y and P2X receptors. Neuropharmacology 104, 31-49. doi: 10.1016/j.neuropharm. 2015.12.001

Johansson, S. M., Lindgren, E., Yang, J. N., Herling, A. W., and Fredholm, B. B. (2008). Adenosine A1 receptors regulate lipolysis and lipogenesis in mouse adipose tissue-interactions with insulin. Eur. J. Pharmacol. 597, 92-101. doi: 10.1016/j.ejphar.2008.08.022

Johnston-Cox, H., Eisenstein, A. S., Koupenova, M., Carroll, S., and Ravid, K. (2014). The macrophage A2B adenosine receptor regulates tissue insulin sensitivity. PLOS ONE 9:e98775. doi: 10.1371/journal.pone.0098775

Johnston-Cox, H., Koupenova, M., Yang, D., Corkey, B., Gokce, N., Farb, M. G., et al. (2012). The A2b adenosine receptor modulates glucose homeostasis and obesity. PLOS ONE 7:e40584. doi: 10.1371/journal.pone.0040584

Junger, W. G. (2011). Immune cell regulation by autocrine purinergic signalling. Nat. Rev. Immunol. 11, 201-212. doi: 10.1038/nri2938

Kawano, S., Otsu, K., Kuruma, A., Shoji, S., Yanagida, E., Muto, Y., et al. (2006). ATP autocrine/paracrine signaling induces calcium oscillations and NFAT activation in human mesenchymal stem cells. Cell Calcium 39, 313-324. doi: $10.1016 /$ j.ceca.2005.11.008

Kim, S. H., and Plutzky, J. (2016). Brown fat and browning for the treatment of obesity and related metabolic disorders. Diabetes Metab. J. 40, 12-21. doi: $10.4093 / \mathrm{dmj} .2016 .40 .1 .12$

Kusminski, C. M., Bickel, P. E., and Scherer, P. E. (2016). Targeting adipose tissue in the treatment of obesity-associated diabetes. Nat. Rev. Drug Discov. 15, 639-660. doi: 10.1038/nrd.2016.75

Laplante, M. A., Monassier, L., Freund, M., Bousquet, P., and Gachet, C. (2010). The purinergic $\mathrm{P} 2 \mathrm{Y} 1$ receptor supports leptin secretion in adipose tissue. Endocrinology 151, 2060-2070. doi: 10.1210/en.2009-1134

Larrouy, D., Galitzky, J., and Lafontan, M. (1991). A1 adenosine receptors in the human fat cell: tissue distribution and regulation of radioligand binding. Eur. J. Pharmacol. 206, 139-147. doi: 10.1016/0922-4106(91)90022-A

Lazarowski, E. R. (2012). Vesicular and conductive mechanisms of nucleotide release. Purinergic Signal. 8, 359-373. doi: 10.1007/s11302-012-9304-9

Lee, H., Jun, D. J., Suh, B. C., Choi, B. H., Lee, J. H., Do, M. S., et al. (2005). Dual roles of P2 purinergic receptors in insulin-stimulated leptin production and lipolysis in differentiated rat white adipocytes. J. Biol. Chem. 280, 28556-28563. doi: $10.1074 /$ jbc.M411253200

Lee, S. C., Vielhauer, N. S., Leaver, E. V., and Pappone, P. A. (2005). Differential regulation of $\mathrm{ca}(2+)$ signaling and membrane trafficking by multiple $\mathrm{p} 2$ receptors in brown adipocytes. J. Membr. Biol. 207, 131-142. doi: 10.1007/ s00232-005-0808-x

Lee, S. C., and Pappone, P. A. (1997a). Effects of P2 purinergic receptor stimulation in brown adipocytes. Am. J. Physiol. 273(2 Pt 1), C679-C686.

Lee, S. C., and Pappone, P. A. (1997b). Membrane responses to extracellular ATP in rat isolated white adipocytes. Pflugers Arch. 434, 422-428. doi: 10.1007/ s004240050416

Lemaire, A., Vanorle, M., Horckmans, M., di Pietrantonio, L., Clouet, S., Robaye, B., et al. (2017). Mouse P2Y4 nucleotide receptor is a negative regulator of cardiac adipose-derived stem cell differentiation and cardiac fat formation. Stem Cells Dev. 26, 363-373. doi: 10.1089/scd.2016.0166 
Li, W., Li, G., Zhang, Y., Wei, S., Song, M., Wang, W., et al. (2015). Role of P2 x 7 receptor in the differentiation of bone marrow stromal cells into osteoblasts and adipocytes. Exp. Cell Res. 339, 367-379. doi: 10.1016/j.yexcr.2015.10.011

Li, W., Wei, S., Liu, C., Song, M., Wu, H., and Yang, Y. (2016). Regulation of the osteogenic and adipogenic differentiation of bone marrow-derived stromal cells by extracellular uridine triphosphate: the role of $\mathrm{P} 2 \mathrm{Y} 2$ receptor and ERK1/2 signaling. Int. J. Mol. Med. 37, 63-73. doi: 10.3892/ijmm.2015.2400

Madec, S., Rossi, C., Chiarugi, M., Santini, E., Salvati, A., Ferrannini, E., et al. (2011). Adipocyte P2X7 receptors expression: a role in modulating inflammatory response in subjects with metabolic syndrome? Atherosclerosis 219, 552-558. doi: 10.1016/j.atherosclerosis.2011.09.012

Mersmann, H. J., Carey, G. B., and Smith, E. O. (1997). Adipose tissue betaadrenergic and A1 adenosine receptors in suckling pigs. J. Anim. Sci. 75, 3161-3168. doi: 10.2527/1997.75123161x

North, R. A. (2016). P2X receptors. Philos. Trans. R. Soc. Lond. B Biol. Sci. 371:20150427. doi: 10.1098/rstb.2015.0427

Novak, I. (2011). Purinergic signalling in epithelial ion transport: regulation of secretion and absorption. Acta Physiol. (Oxf). 202, 501-522. doi: 10.1111/j. 1748-1716.2010.02225.x

Pandolfi, J., Ferraro, A., Lerner, M., Serrano, J. R., Dueck, A., Fainboim, L., et al. (2015). Purinergic signaling modulates human visceral adipose inflammatory responses: implications in metabolically unhealthy obesity. J. Leukoc. Biol. 97, 941-949. doi: 10.1189/jlb.3A1214-626R

Pandolfi, J. B., Ferraro, A. A., Sananez, I., Gancedo, M. C., Baz, P., Billordo, L. A., et al. (2016). ATP-induced inflammation drives tissue-resident Th17 cells in metabolically unhealthy obesity. J. Immunol. 196, 3287-3296. doi: 10.4049/ jimmunol.1502506

Peleli, M., and Carlstrom, M. (2017). Adenosine signaling in diabetes mellitus and associated cardiovascular and renal complications. Mol. Aspects Med. 55, 62-74. doi: 10.1016/j.mam.2016.12.001

Peleli, M., Hezel, M., Zollbrecht, C., Persson, A. E., Lundberg, J. O., Weitzberg, E., et al. (2015). In adenosine A2B knockouts acute treatment with inorganic nitrate improves glucose disposal, oxidative stress, and AMPK signaling in the liver. Front. Physiol. 6:222. doi: 10.3389/fphys.2015.00222

Rancoule, C., Dusaulcy, R., Treguer, K., Gres, S., Attane, C., and Saulnier-Blache, J. S. (2014). Involvement of autotaxin/lysophosphatidic acid signaling in obesity and impaired glucose homeostasis. Biochimie 96, 140-143. doi: 10.1016/j.biochi. 2013.04.010

Razzoli, M., Frontini, A., Gurney, A., Mondini, E., Cubuk, C., Katz, L. S., et al. (2016). Stress-induced activation of brown adipose tissue prevents obesity in conditions of low adaptive thermogenesis. Mol. Metab. 5, 19-33. doi: 10.1016/j. molmet.2015.10.005

Rice, A. M., Fain, J. N., and Rivkees, S. A. (2000). A1 adenosine receptor activation increases adipocyte leptin secretion. Endocrinology 141, 1442-1445. doi: 10.1210/endo.141.4.7423

Rissiek, B., Haag, F., Boyer, O., Koch-Nolte, F., and Adriouch, S. (2015). P2X7 on mouse $\mathrm{T}$ cells: one channel, many functions. Front. Immunol. 6:204. doi: 10.3389/fimmu.2015.00204

Saggerson, E. D., and Jamal, Z. (1990). Differences in the properties of A1-type adenosine receptors in rat white and brown adipocytes. Biochem. J. 269, 157-161. doi: 10.1042/bj2690157

Schimmel, R. J., and McCarthy, L. (1984). Role of adenosine as an endogenous regulator of respiration in hamster brown adipocytes. Am. J. Physiol. 246(3 Pt 1), C301-C307.

Schodel, J., Weise, I., Klinger, R., and Schmidt, M. (2004). Stimulation of lipogenesis in rat adipocytes by ATP, a ligand for P2-receptors. Biochem. Biophys. Res. Commun. 321, 767-773. doi: 10.1016/j.bbrc.2004.06.179

Schoelch, C., Kuhlmann, J., Gossel, M., Mueller, G., Neumann-Haefelin, C., Belz, U., et al. (2004). Characterization of adenosine-A1 receptor-mediated antilipolysis in rats by tissue microdialysis, $1 \mathrm{H}$-spectroscopy, and glucose clamp studies. Diabetes Metab. Res. Rev. 53, 1920-1926. doi: 10.2337/diabetes.53.7. 1920

Shah, B., Rohatagi, S., Natarajan, C., Kirkesseli, S., Baybutt, R., and Jensen, B. K. (2004). Pharmacokinetics, pharmacodynamics, and safety of a lipid-lowering adenosine A1 agonist, RPR749, in healthy subjects. Am. J. Ther. 11, 175-189. doi: 10.1097/00045391-200405000-00005

Staehr, P. M., Dhalla, A. K., Zack, J., Wang, X., Ho, Y. L., Bingham, J., et al. (2013). Reduction of free fatty acids, safety, and pharmacokinetics of oral GS-9667, an A(1) adenosine receptor partial agonist. J. Clin. Pharmacol. 53, 385-392. doi: $10.1002 /$ jcph.9

Strong, P., Anderson, R., Coates, J., Ellis, F., Evans, B., Gurden, M. F., et al. (1993). Suppression of non-esterified fatty acids and triacylglycerol in experimental animals by the adenosine analogue GR79236. Clin. Sci. (Lond). 84, 663-669. doi: $10.1042 / \operatorname{cs} 0840663$

Sun, S., Xia, S., Ji, Y., Kersten, S., and Qi, L. (2012). The ATP-P2X7 signaling axis is dispensable for obesity-associated inflammasome activation in adipose tissue. Diabetes Metab. Res. Rev. 61, 1471-1478. doi: 10.2337/db11-1389

Szkudelski, T., Szkudelska, K., and Nogowski, L. (2009). Effects of adenosine A1 receptor antagonism on lipogenesis and lipolysis in isolated rat adipocytes. Physiol. Res. 58, 863-871.

Tatsis-Kotsidis, I., and Erlanger, B. F. (1999). A1 adenosine receptor of human and mouse adipose tissues: cloning, expression, and characterization. Biochem. Pharmacol. 58, 1269-1277. doi: 10.1016/S0006-2952(99)00214-2

Trost, T., and Schwabe, U. (1981). Adenosine receptors in fat cells. Identification by (-)-N6-[3H] phenylisopropyladenosine binding. Mol. Pharmacol. 19, 228-235.

Ussar, S., Lee, K. Y., Dankel, S. N., Boucher, J., Haering, M. F., Kleinridders, A., et al. (2014). ASC-1, PAT2, and P2RX5 are cell surface markers for white, beige, and brown adipocytes. Sci. Transl. Med. 6:247ra103. doi: 10.1126/scitranslmed. 3008490

von Kugelgen, I., and Hoffmann, K. (2016). Pharmacology and structure of P2Y receptors. Neuropharmacology 104, 50-61. doi: 10.1016/j.neuropharm.2015. 10.030

Woodward, J. A., and Saggerson, E. D. (1986). Effect of adenosine deaminase, N6-phenylisopropyladenosine and hypothyroidism on the responsiveness of rat brown adipocytes to noradrenaline. Biochem. J. 238, 395-403. doi: 10.1042/ bj2380395

Wu, L., Belardinelli, L., Zablocki, J. A., Palle, V., and Shryock, J. C. (2001). A partial agonist of the $\mathrm{A}(1)$-adenosine receptor selectively slows AV conduction in guinea pig hearts. Am. J. Physiol. Heart Circ. Physiol. 280, H334-H343.

Yang, T., Gao, X., Sandberg, M., Zollbrecht, C., Zhang, X. M., Hezel, M., et al. (2015). Abrogation of adenosine A1 receptor signalling improves metabolic regulation in mice by modulating oxidative stress and inflammatory responses. Diabetologia 58, 1610-1620. doi: 10.1007/s00125-0153570-3

Yang, T., Zollbrecht, C., Winerdal, M. E., Zhuge, Z., Zhang, X. M., Terrando, N., et al. (2016). Genetic abrogation of adenosine A3 receptor prevents uninephrectomy and high salt-induced hypertension. J. Am. Heart Assoc. 5:e003868. doi: 10.1161/JAHA.116.003868

Yu, Z., and Jin, T. (2010). Extracellular high dosages of adenosine triphosphate induce inflammatory response and insulin resistance in rat adipocytes. Biochem. Biophys. Res. Commun. 402, 455-460. doi: 10.1016/j.bbrc.2010.10.028

Zannikos, P. N., Rohatagi, S., and Jensen, B. K. (2001). Pharmacokineticpharmacodynamic modeling of the antilipolytic effects of an adenosine receptor agonist in healthy volunteers. J. Clin. Pharmacol. 41, 61-69. doi: 10.1177/ 00912700122009845

Zimmermann, H., Zebisch, M., and Strater, N. (2012). Cellular function and molecular structure of ecto-nucleotidases. Purinergic Signal. 8, 437-502. doi: 10.1007/s11302-012-9309-4

Zippel, N., Limbach, C. A., Ratajski, N., Urban, C., Luparello, C., Pansky, A., et al. (2012). Purinergic receptors influence the differentiation of human mesenchymal stem cells. Stem Cells Dev. 21, 884-900. doi: 10.1089/scd.2010. 0576

Conflict of Interest Statement: The authors declare that the research was conducted in the absence of any commercial or financial relationships that could be construed as a potential conflict of interest.

The reviewer GY declared a past co-authorship with one of the authors IN to the handling Editor.

Copyright (c) 2017 Tozzi and Novak. This is an open-access article distributed under the terms of the Creative Commons Attribution License (CC BY). The use, distribution or reproduction in other forums is permitted, provided the original author(s) or licensor are credited and that the original publication in this journal is cited, in accordance with accepted academic practice. No use, distribution or reproduction is permitted which does not comply with these terms. 